Pedro M. Rodrigues • Anjos L. Macedo

Brian J. Goodfellow • Isabel Moura · José J. G. Moura

\title{
Desulfovibrio gigas ferredoxin II: redox structural modulation of the [3Fe-4S] cluster
}

Received: 22 July 2005/ Accepted: 22 December 2005/Published online: 2 February 2006

(C) SBIC 2006

\begin{abstract}
Desulfovibrio gigas ferredoxin II (DgFdII) is a small protein with a polypeptide chain composed of 58 amino acids, containing one $\mathrm{Fe}_{3} \mathrm{~S}_{4}$ cluster per monomer. Upon studying the redox cycle of this protein, we detected a stable intermediate $\left(\mathrm{FdII}_{\text {int }}\right)$ with four ${ }^{1} \mathrm{H}$ resonances at 24.1, 20.5, 20.8 and $13.7 \mathrm{ppm}$. The differences between $\mathrm{FdII}_{\mathrm{ox}}$ and $\mathrm{FdII}_{\text {int }}$ were attributed to conformational changes resulting from the breaking/formation of an internal disulfide bridge. The same ${ }^{1} \mathrm{H}$ NMR methodology used to fully assign the three cysteinyl ligands of the $[3 \mathrm{Fe}-4 \mathrm{~S}]$ core in the oxidized state $\left(D g \mathrm{FdII}_{\mathrm{ox}}\right)$ was used here for the assignment of the same three ligands in the intermediate state $\left(D g F d I I_{\text {int }}\right)$. The spin-coupling model used for the oxidized form of $D g$ FdII where magnetic exchange coupling constants of around $300 \mathrm{~cm}^{-1}$ and hyperfine coupling constants equal to $1 \mathrm{MHz}$ for all the three iron centres were found, does not explain the isotropic shift temperature dependence for the three cysteinyl cluster ligands in $D g F d I_{\text {int }}$. This study, together with the spin delocalization mechanism proposed here for $D g \mathrm{FdII}_{\text {int }}$, allows the detection of structural modifications at the $[3 \mathrm{Fe}-4 \mathrm{~S}]$ cluster in $D g \mathrm{FdII}_{\mathrm{ox}}$ and $D g \mathrm{FdII}_{\text {int }}$.
\end{abstract}

Keywords $\mathrm{Fe}_{3} \mathrm{~S}_{4}$ cluster $\cdot$ Ferredoxin $\cdot$ Disulfide bridge $\cdot$ Paramagnetic protein $\cdot$ Desulfovibrio gigas

P. M. Rodrigues

FCMA, CCMAR, Universidade do Algarve,

Campus de Gambelas, 8005-139 Faro, Portugal

\footnotetext{
A. L. Macedo · I. Moura · J. J. G. Moura (ه)

REQUIMTE, Departamento de Química,

Centro de Química Fina e Biotecnologia,

Faculdade de Ciências e Tecnologia,

Universidade Nova de Lisboa, 2829-516 Caparica,

Portugal

E-mail: jose.moura@dq.fct.unl.pt

Tel.: + 351-21-2954464

Fax: + 351-21-2948550

B. J. Goodfellow

Departamento de Química, Universidade de Aveiro, 3810 Aveiro, Portugal
}

Abbreviations Dg: Desulfovibrio gigas $\cdot \mathrm{Fd}$ : Ferredoxin - NOE: Nuclear Overhauser effect - NOESY: Nuclear Overhauser enhancement spectroscopy $\cdot$ SRB: Sulfate-reducing bacteria

\section{Introduction}

Ferredoxins (Fds) are simple electron transfer proteins with iron and sulfide at the active site, with cysteinyl sulfur atoms as cluster terminal ligands (other atoms, such as $\mathrm{O}$ or N, may be involved) [1]. Since the discovery of these proteins 40 years ago, many other proteins containing $[\mathrm{Fe}-\mathrm{S}]$ clusters of distinct types have been discovered [2-4]. The existence of different types of [FeS] proteins and clusters points to a remarkable functional and structural diversity, reflecting the chemical versatility of both iron and sulfur [3, 4]. The known functions of biological $[\mathrm{Fe}-\mathrm{S}]$ clusters include electron transfer in Fds and redox enzymes [1, 5-7], coupled electron/proton transfer [8], substrate binding and activation [9-19], Fe or cluster storage [20], structural control [21-23], regulation of gene expression [24-31] and enzyme activity [32-34], disulfide reduction [35-37] and sulfur donation [38-40].

Four distinct types of $\mathrm{Fds}$ are found in sulfatereducing bacteria (SRB), where they play a relevant metabolic role: $3 \mathrm{Fe} \mathrm{Fd}$ containing one [ $3 \mathrm{Fe}-4 \mathrm{~S}], 4 \mathrm{Fe} \mathrm{Fd}$ containing one $[4 \mathrm{Fe}-4 \mathrm{~S}], 7 \mathrm{Fe}$ Fd containing a $[3 \mathrm{Fe}-4 \mathrm{~S}]$ and a $[4 \mathrm{Fe}-4 \mathrm{~S}]$ cluster, and $8 \mathrm{Fe} \mathrm{Fd} \mathrm{containing} \mathrm{two} \mathrm{[4Fe-}$ 4S] clusters [41].

Desulfovibrio gigas $(D g) \mathrm{FdII}$ is a small protein, of 58 amino acids with 1 [3Fe-4S] cluster per monomer $[42,43]$ investigations. In the native state the protein is a tetramer. The three-dimensional structure has already been established by X-ray [44] and also by NMR [45]. Cys8, Cys14 and Cys50 bind the cluster; Cys11 is available to bind the fourth ligand in $\mathrm{FdI}$ that contains a [4Fe-4S] cluster. The two remaining cysteines, Cys 18 and Cys42, form a disulfide bridge in the native state $[44,46]$. $D g F d I I$ can be converted to FdI following incubation with excess 
$\mathrm{Fe}^{2+}$ in the presence of dithiothreitol [47], showing that the polypeptide chain of $D g F d$ can accommodate both $[3 \mathrm{Fe}-4 \mathrm{~S}]$ and $[4 \mathrm{Fe}-4 \mathrm{~S}]$ clusters. This cluster interconversion leads to the incorporation of other transition metals into the $[3 \mathrm{Fe}-4 \mathrm{~S}]$ cluster, with the $[\mathrm{Co}, 3 \mathrm{Fe}-4 \mathrm{~S}]$ heterometal centre in $D g F$ dII being the first reported [48], and similar results were subsequently found for D. africanus FdIII [49] and Pyrococcus furiosus Fd [50]. Other $[\mathrm{Zn}, 3 \mathrm{Fe}-4 \mathrm{~S}]$ and $[\mathrm{Ni}, 3 \mathrm{Fe}-4 \mathrm{~S}]$ centres were also produced from this protein $[51,52]$. This interconversion mechanism and the cluster geometries appear to have physiological significance between the oxidized and reduced states. Recently, the crystallization of $D g F d I I$ under an anaerobic environment gave crystals which diffracted at a resolution of $1.37 \AA$ [53].

The $[3 \mathrm{Fe}-4 \mathrm{~S}]$ cluster can be stabilized in two oxidation states: $[3 \mathrm{Fe}-4 \mathrm{~S}]^{+}$and $[3 \mathrm{Fe}-4 \mathrm{~S}]^{0}$. In the oxidized state, the three high-spin ferric atoms $(S=5 / 2)$ are antiferromagnetically coupled, forming a ground electronic state with a global spin of $1 / 2$ [54]. One-electron reduction gives an $S=2$ state, resulting from the antiferromagnetic coupling between a delocalized iron pair $(S=9 / 2)$, that share the incoming electron, and a highspin iron(III) site $(S=5 / 2)$, as indicated by Mössbauer investigations $[47,55,56]$. Electrochemical studies of the 7Fe Fds from D. africanus FdIII [49, 57], Azotobacter vinelandii FdI [58] and Sulfolobulus acidocaldarius [59] suggest that further reduction of the cluster leads to a formal $[3 \mathrm{Fe}-4 \mathrm{~S}]^{2-}$ oxidation state. Similar observations of the detection of an all-ferrous state were also reported for $D g \mathrm{FdII}[52]$ and the $3 \mathrm{Fe}$ interconverted form of $P$. furiosus $\mathrm{Fd}[60]$.

The specific assignment of the $\beta-\mathrm{CH}_{2}$ protons of the cysteinyl cluster ligands was made, for $\mathrm{FdII}_{\text {ox }}$, by ${ }^{1} \mathrm{H}$ NMR [61, 62]. These protons are affected by the cluster paramagnetism and their chemical shift temperature dependence was used to study the electronic properties of the cluster. On the basis of the coupling model for the cluster iron atoms $[63,64]$, the NMR data allowed the determination of the iron coupling constants [62]. The temperature dependence of these $\beta-\mathrm{CH}_{2}$ protons showed one pair could be assigned to Cys50 with Curie dependence and the other two pairs belonged to Cys8 and Cys14 with anti-Curie behaviour [61, 62]. This can be explained assuming different exchange coupling interactions between the three iron atoms that coordinate the cysteines, with $J_{13}=J_{23}=J$ and $J_{12}=J+\Delta J$ $(\Delta J>0)$. Values of $J \approx 300 \mathrm{~cm}^{-1}$ and $\Delta J / J \approx 0.02$ were found to fit the experimental data [62]. The reported $J$ values that better reproduce the experimental NMR data for both the [3Fe-4S] clusters of the $\mathrm{Fe}_{7} \mathrm{~S}_{8} \mathrm{Fds}$ from Bacillus schlegelii [65] and Rhodopseudomonas palustris [66] were also determined and were found to be around $300 \mathrm{~cm}^{-1}$. The $J$ values determined were, respectively, $J_{12}=320, J_{23}=280$ and $J_{13}=290 \mathrm{~cm}^{-1}$ for B. schlegelii and $J_{12}=285, J_{13}=300$ and $J_{23}=320 \mathrm{~cm}^{-1}$ for $R$. palustris. Comparing these values with those for DgFdII we can observe that the magnetic interaction within the $[3 \mathrm{Fe}-4 \mathrm{~S}]$ cluster is less symmetric in $\mathrm{Fe}_{7} \mathrm{~S}_{8} \mathrm{Fds}$, agreeing with the fact that in those last two cases, one cysteinyl $\beta-\mathrm{CH}_{2}$ proton displays an upfield-shifted signal that is not present in the single-cluster FdII protein from $D g$ [62].

NMR also proved to be a very sensitive tool to detect structural alterations, allowing the detection of a stable intermediate state $\left(\mathrm{FdII}{ }_{\text {int }}\right)$ in the potential range around $-130 \mathrm{mV}$, where the cluster is reduced from the +1 to the 0 state [46]. FdII int was characterized by Mössbauer and electron paramagnetic resonance techniques, showing that the $[3 \mathrm{Fe}-4 \mathrm{~S}]$ cluster remains in the oxidized state [47]. The differences in the NMR and Mössbauer spectra between $\mathrm{FdII}_{\mathrm{ox}}$ and $\mathrm{FdII}_{\text {int }}$ were due to conformational changes resulting from the breaking/formation of the disulfide bridge. The same intermediate state was found later in the P. furiosus 4Fe Fd [67]. This may turn out to be a key observation for the mechanism of complex proteins containing iron-sulfur clusters.

We will present a characterization of that intermediate state $\left(\mathrm{FdII}_{\mathrm{int}}\right)$ in terms of the electronic properties of the cluster and structural rearrangements of the cluster vicinity, using NMR spectroscopy.

\section{Materials and methods}

\section{Protein purification}

$D g$ FdII was purified as previously described [42] with a slight modification: the last purification step was performed in a gel filtration prepacked Pharmacia column (Superdex 75 HR 10/30) by high-performance liquid chromatography, and elution was made with $50 \mathrm{mM}$ phosphate buffer at $\mathrm{pH} 7.6$ with $\mathrm{NaCl} 150 \mathrm{mM}$. The purified protein solutions were simultaneously concentrated, equilibrated with $100 \mathrm{mM}$ phosphate buffer at $\mathrm{pH} 8.0$ and exchanged with $99.9 \% \mathrm{D}_{2} \mathrm{O}$ using AMICON centricons with a 5-kDa cutoff.

\section{Sample preparation}

The intermediate state, $\mathrm{FdII}_{\text {int }}$, was generated by adding proper amounts of sodium dithionite to the native protein under anaerobic conditions. EDTA was present to prevent $[4 \mathrm{Fe}-4 \mathrm{~S}]$ cluster formation.

\section{NMR experiments}

High-resolution NMR spectra were recorded either with $400-\mathrm{MHz}$ ARX or $600-\mathrm{MHz}$ AMX Fourier transform Bruker spectrometers equipped with a temperaturecontrol unit. Chemical shift values are quoted in parts per million relative to 3 -trimethylsilyl- $\left(2,2,3,3-{ }^{2} \mathrm{H}_{4}\right)$ propionate. Positive values refer to low-field shifts. $T_{1}$ measurements were made using the inversion-recovery method [68]. The proton nuclear Overhauser effect (NOE) experiments were performed either at $400 \mathrm{MHz}$ or at $600 \mathrm{MHz}$ using the super-WEFT pulse sequence 
(180- $\tau-90-A Q)[69]$ with $\tau$ values and recycle times, 100 $200 \mathrm{~ms}$, providing water suppression. Selective saturation of the resonances was made during the delay time $\tau$. Difference spectra were obtained by subtracting the offresonance spectra from the on-resonance spectra, as described in Ref. [70]. Two-dimensional experiments were carried out at $400 \mathrm{MHz}$. Phase-sensitive nuclear Overhauser enhancement spectroscopy (NOESY) [71, 72] spectra were recorded with mixing times around $5 \mathrm{~ms}$, with $1,024 t_{2}$ points and $256 t_{1}$ increments and $3,000-4,000$ scans per increment. Repetition times were 75-100 ms. In the processing, before Fourier transformation the data were multiplied by an unshifted sine-bell window function in the $f_{2}$ dimension and an unshifted sine-bell window function in the $f_{1}$ dimension.

\section{Results}

The intermediate state obtained by dithionite reduction of the native $D g$ FdII is stable for several days, allowing NMR techniques to be easily applied. This state is characterized by a $[3 \mathrm{Fe}-4 \mathrm{~S}]^{+}$centre and a broken $\mathrm{S}-\mathrm{S}$ bridge between Cys18 and Cys42. Both $\mathrm{FdII}_{\mathrm{ox}}$ and FdII $_{\text {int }}$ states have a paramagnetic cluster with $S=1 / 2$, affecting the properties of the resonances for the protons of the ligands bound to the iron atom and those protons within about $8 \AA$ of the cluster [46].

Figure 1 presents the ${ }^{1} \mathrm{H}$ NMR spectrum of a $D g$ FdII sample where the protein is in equilibrium between the oxidized and intermediate states. As previously reported [61], FdII ${ }_{\text {ox }}$ displays four broad resonances at 29.3, 24.4, 16.8 and $15.3 \mathrm{ppm}$, in the low-field region of the spectrum. These resonances (labelled a-d in Fig. 1) were assigned to the $\beta-\mathrm{CH}_{2}$ protons of the three cysteinyl cluster ligands. The sequence-specific assignments are presented in Table 1. Resonance a shows a correlation

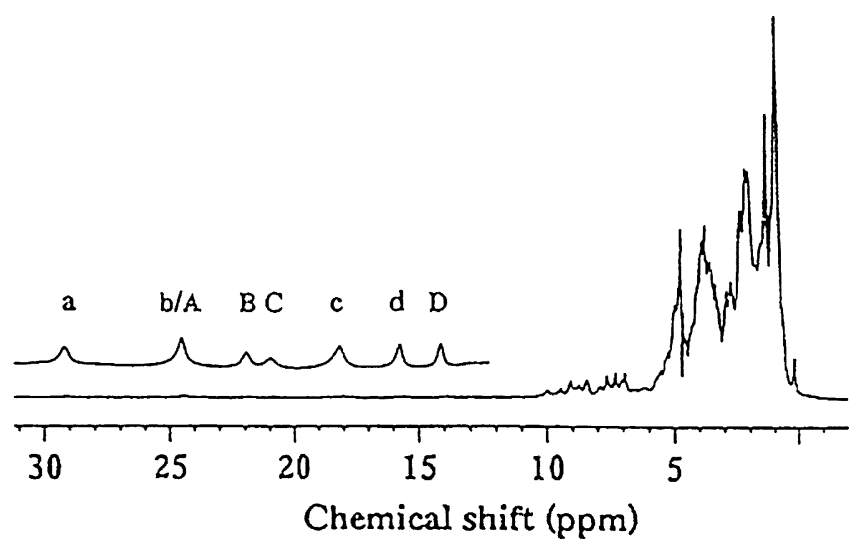

Fig. 1 Complete $400-\mathrm{MHz}{ }^{1} \mathrm{H}$ NMR spectrum (with water suppression) of a mixture of Desulfovibrio gigas $(D g)$ ferredoxin $(F d)$ $\mathrm{II}_{\mathrm{ox}} / D g \mathrm{FdII}_{\text {int }}$ in ${ }^{2} \mathrm{H}_{2} \mathrm{O}(\mathrm{pH} 8.0)$ at $310 \mathrm{~K}$. The upper expanded low-field region has resonances labelled $a-d$ and $A-D$, belonging to the oxidized and intermediate states of $D g \mathrm{FdII}$, respectively. There is $54 \%$ of the mixture in the oxidized state and $46 \%$ in the intermediate state. No reduced state was detected with a resonance at $4.1 \mathrm{ppm}$ in the ${ }^{1} \mathrm{H}$ NOESY spectrum, with a $10 \mathrm{~ms}$ mixing time at $303 \mathrm{~K}$ (not shown), that can be assigned to the $\alpha-\mathrm{CH}$ proton of Cys50, based on the cross-peak intensity. All the protons of the cysteinyl cluster ligands for $\mathrm{FdII}_{\mathrm{ox}}$ have therefore now been sequence-specifically assigned.

The resonances in the low-field region, between 25 and $12 \mathrm{ppm}$ labelled $\mathrm{A}-\mathrm{D}$, belong to the protons of the cysteinyl cluster ligands of the intermediate state. The temperature behaviour and assignment of these resonances was carried out using ${ }^{1} \mathrm{H}$ NOESY experiments, performed with different mixing times $(2-10 \mathrm{~ms})$ and at different temperatures (290-310 K).

The connectivities detected in the 8-ms NOESY spectrum of a mixture of $\mathrm{FdII}_{\mathrm{ox}}(40 \%) / \mathrm{FdII}_{\text {int }}(60 \%)$ are shown in Fig. 2. The percentage of each species was estimated by integrating peaks $\mathrm{d}$ and $\mathrm{D}$ from the oxidized and intermediate states, respectively. The connectivities detected between resonances $\mathrm{A}$ and $\mathrm{C}, \mathrm{B}$ and a resonance at $8.7 \mathrm{ppm}$, and $\mathrm{D}$ and a resonance at $7.8 \mathrm{ppm}$ allow these resonances to be assigned to the three $\beta-\mathrm{CH}_{2}$ protons of the cysteinyl cluster ligands, in the intermediate state. Resonance $\mathrm{B}$ also shows a correlation with a resonance at $1.4 \mathrm{ppm}$, as does resonance $\mathrm{D}$ with a resonance at $9.8 \mathrm{ppm}$. On the basis of the intensity of the observed cross peaks and the $T_{1}$ value $\left(T_{1}\right.$ values for resonances $\mathrm{A}-\mathrm{D}$ and the resonance at $9.8 \mathrm{ppm}$ are listed in Table 1) for the resonance at $9.8 \mathrm{ppm}$, we can assign both 1.4- and 9.8-ppm resonances to $\alpha-\mathrm{CH}$ protons.

In order to attempt the sequence-specific assignment of the hyperfine shifted resonances, one-dimensional NOE difference experiments were carried out for $\mathrm{FdII}_{\text {int }}$. The experiment (not shown) allowed the specific assignment of peak $\mathrm{D}$ and the peak at $7.8 \mathrm{ppm}$ to the $\beta$ $\mathrm{CH}_{2}$ protons of Cys14. Saturation of peak D showed a NOE effect with the proton resonances of the aromatic ring of Phe22, which have been previously assigned [61]. Using the X-ray coordinates [44], Phe22, the only aromatic residue present in the protein, is close enough (3$4.7 \AA$ for one $\beta-\mathrm{CH}_{2}$ and 5-5.5 $\AA$ for the other) to display a NOE effect with $\beta-\mathrm{CH}_{2}$ protons of Cys14. The one-dimensional NOE experiments when the other hyperfine shifted peaks were irradiated did not show any extra NOEs apart from those for their $\beta-\mathrm{CH}_{2}$ or $\alpha-\mathrm{CH}$ partner.

The temperature dependencies of the chemical shifts of the three $\beta-\mathrm{CH}_{2}$ pairs of cysteine protons for both the oxidized state (resonances a-d, 8.6 and $3.0 \mathrm{ppm}$ ) and the intermediate state (resonances $\mathrm{A}-\mathrm{D}, 8.7$ and $7.8 \mathrm{ppm}$ ) areplotted in Fig. 3. The resonances of the oxidized state attributed to the $\beta-\mathrm{CH}_{2}$ protons of $\mathrm{Cys} 50$ have Curie dependence, while all the other $\beta-\mathrm{CH}_{2}$ protons have antiCurie dependence [61]. The intermediate state shows similar behaviour: resonance $\mathrm{D}$ and the resonance at 7.8 ppm (Cys14) have Curie temperature dependence, while resonances $\mathrm{A}-\mathrm{C}$ and the resonance at $8.7 \mathrm{ppm}$ have anti-Curie dependence. By comparing the chemical shifts and slopes of the temperature dependencies it was 
Table 1 Summary of the NMR spectral parameters and assignment of the coordinated cysteinyl proton resonances, for both Desulfovibrio gigas $(\mathrm{Dg})$ ferredoxin $(F d) \mathrm{II}_{\mathrm{ox}}$ and $D g \mathrm{FdII}_{\text {int }}$ at $300 \mathrm{~K}$

\begin{tabular}{|c|c|c|c|c|c|}
\hline \multirow[t]{2}{*}{ Cys } & \multirow[t]{2}{*}{ Protons } & \multicolumn{2}{|l|}{$D g \mathrm{FdII}_{\mathrm{ox}}[61]$} & \multicolumn{2}{|l|}{$D g \mathrm{FdII}_{\mathrm{int}}$} \\
\hline & & Signal (ppm) & $T_{1}(\mathrm{~ms})$ & Signal (ppm) & $T_{1}(\mathrm{~ms})$ \\
\hline \multirow[t]{3}{*}{50} & $\beta-\mathrm{CH}$ & a (29.3) & 4.3 & A $(24.1)$ & 3.6 \\
\hline & $\beta-\mathrm{CH}$ & b (24.4) & 3.1 & C (20.5) & 3.0 \\
\hline & $\alpha-\mathrm{CH}$ & $(4.1)$ & ND & ND & ND \\
\hline \multirow[t]{3}{*}{14} & $\beta-\mathrm{CH}$ & d (15.3) & 7.0 & D (13.7) & 5.8 \\
\hline & $\beta-\mathrm{CH}$ & $(8.6)$ & ND & $(7.8)$ & ND \\
\hline & $\alpha-\mathrm{CH}$ & $(9.7)$ & ND & $(9.8)$ & 16.4 \\
\hline \multirow[t]{3}{*}{8} & $\beta-\mathrm{CH}$ & c (16.8) & 4.0 & B (20.8) & 3.2 \\
\hline & $\beta-\mathrm{CH}$ & $(3.0)$ & ND & $(8.7)$ & ND \\
\hline & $\alpha-\mathrm{CH}$ & (1.43) & ND & (1.4) & ND \\
\hline
\end{tabular}

$N D$ not determined

possible to tentatively assign, for $\mathrm{FdII}_{\mathrm{int}}$, resonances $\mathrm{A}$ and $\mathrm{C}$ to the $\beta-\mathrm{CH}_{2}$ protons of Cys50 and resonance $\mathrm{B}$ and the resonance at $8.7 \mathrm{ppm}$ to Cys8. It is interesting to note that Cys14 now appears as the least shifted $\beta-\mathrm{CH}_{2}$ proton resonance and displays Curie temperature behaviour.

In order to probe the structural changes at the cluster for $\mathrm{FdII}_{\text {int }}$ a plot of the contact chemical shifts of the cysteinyl $\beta-\mathrm{CH}_{2}$ protons versus the corresponding $\mathrm{Fe}-\mathrm{S}-\mathrm{C} \beta-\mathrm{C} \alpha$ dihedral angles $(\theta)$ for $3 \mathrm{Fe} \mathrm{Fds}$ was made (Fig. 4). The experimental chemical shifts available for the $\beta-\mathrm{CH}_{2}$ protons of $D g \mathrm{FdII}$, Thermococus litoralis $3 \mathrm{Fe} \mathrm{Fd}[73,74]$ and $A$. vinelandii $7 \mathrm{Fe} \mathrm{Fd}[75]$

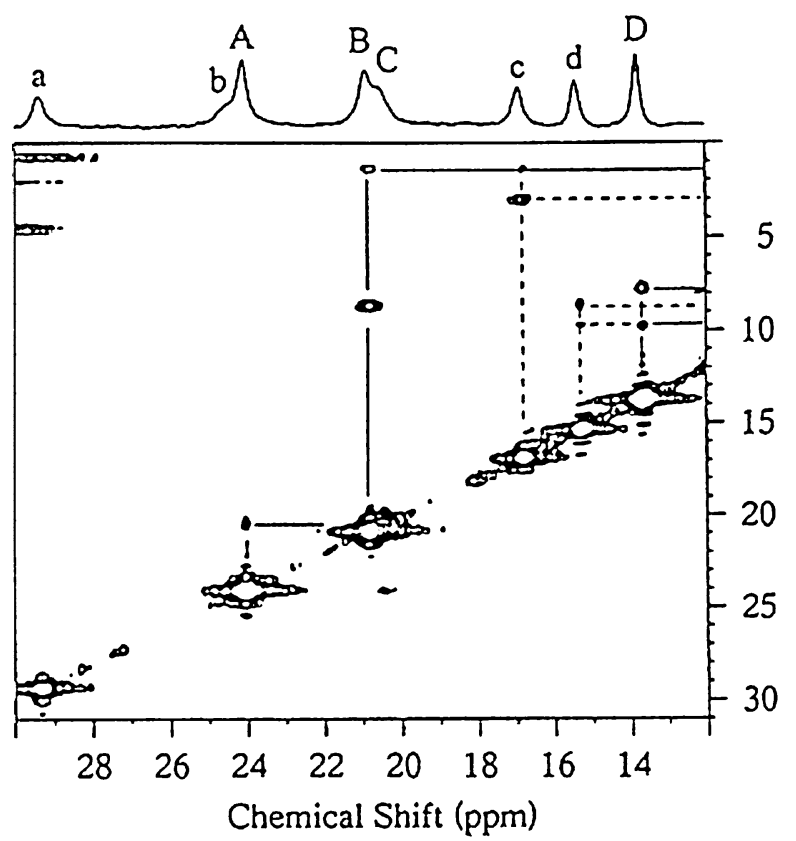

Fig. 2 The $400-\mathrm{MHz}{ }^{1} \mathrm{H}$ nuclear Overhauser enhancement spectroscopy (NOESY) (8-ms mixing time) NMR spectrum of a $D g \mathrm{FdII}_{\mathrm{ox}} / D g \mathrm{FdII}_{\text {int }}$ mixture in ${ }^{2} \mathrm{H}_{2} \mathrm{O}(\mathrm{pH} 8.0)$ at $300 \mathrm{~K}$. Connectivities for $D g \mathrm{FdII}_{\mathrm{ox}}$ signals are indicated by dashed lines. Connectivities for $D g \mathrm{FdII}_{\text {int }}$ are represented by solid lines. Resonances in the one-dimensional ${ }^{1} \mathrm{H}$ NMR spectrum labelled $a-d$ belong to the oxidized state and those labelled $A-D$ to the intermediate state of the protein. The ratio of the oxidized state to the intermediate state was $40 / 60$. No reduced state was detected were used (after subtracting $2.8 \mathrm{ppm}$, the intrinsic diamagnetic chemical shift for a $\beta-\mathrm{CH}_{2}$ proton, and assuming that the contact term is dominant) [76] together with the $\theta$ values from the X-ray crystal structures of $D g$ [44] and $A$. vinelandii [77, 78] Fds. T. litoralis $3 \mathrm{Fe} \mathrm{Fd}$ was used in this fitting considering the similarity between the NMR data from this protein and those from $D g$ FdII. Owing to the absence of X-ray data for this protein, we used the $\theta$ values available
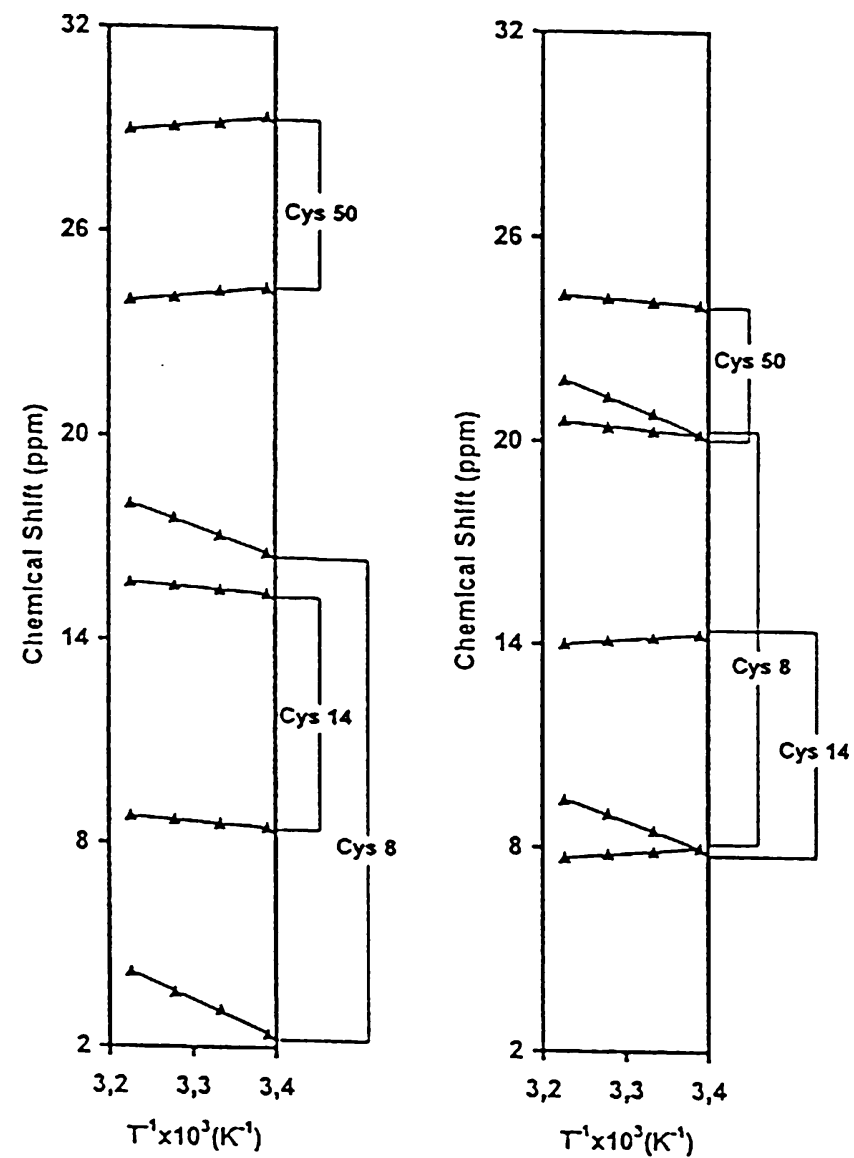

Fig. 3 Experimental temperature dependence of the isotropically shifted ${ }^{1} \mathrm{H}$ NMR signals of $D g \mathrm{FdII}_{\text {ox }}($ left $)$ and $D g \mathrm{FdII}_{\mathrm{int}}($ right $)$ for the assigned cysteinyl residues Cys8, Cys14 and Cys50. The solid lines are not fits of the experimental data; they indicate the trends of the temperature dependencies only 


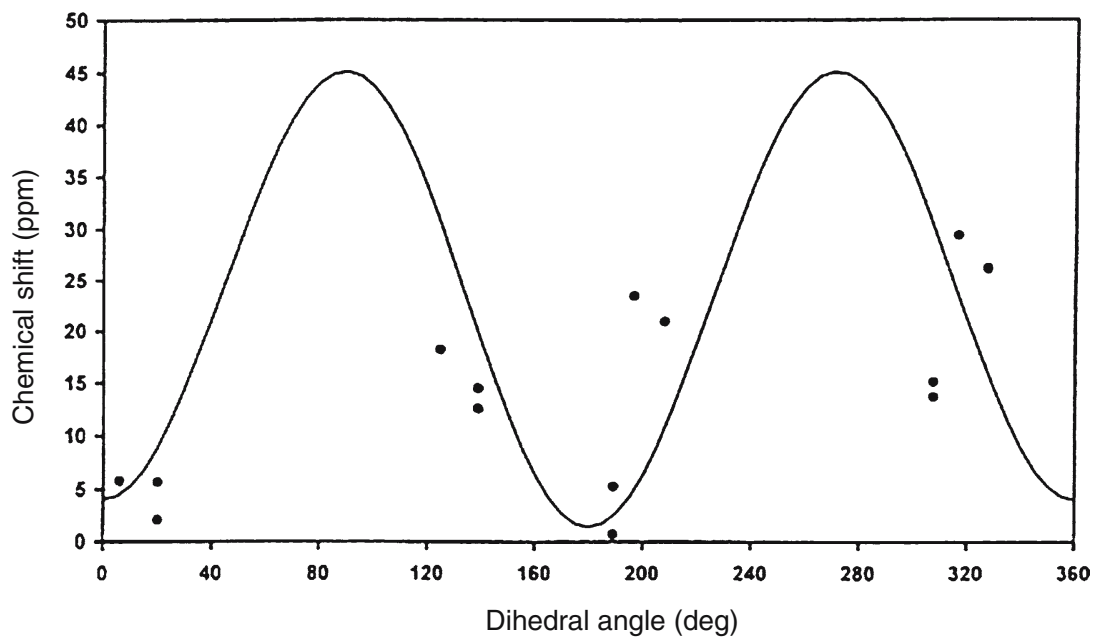

Fig. 4 Best fit for the modified version of the Karplus equation $\delta=a \sin ^{2} \theta+b \cos \theta+c$ for the plot of the contact shifts of the cysteine $\beta-\mathrm{CH}_{2}$ protons vs dihedral angles, $\theta$, for $[3 \mathrm{Fe}-4 \mathrm{~S}]$ systems. The fitting values were $a=41.87, b=-2.82$ and $c=2.88$. A possible error was introduced in both chemical shift and dihedral angle variables. The values used for precision, chemical shift standard

from the X-ray crystal structure of $D g$ FdII. The fitting was obtained using a modified version of Karplus equation $\delta=a \sin ^{2} \theta+b \cos \theta+c$ [79], which accounts for both $\pi$ and $\sigma$ mechanisms of spin delocalization. A possible error in both chemical shift and dihedral angle variables was introduced, since the simulation program takes into account not only the angle error percentage arising from the X-ray structure, but also the error in the chemical shift for each proton of the three different cysteines. The best-fit values obtained for the three parameters gave values of $41.87,-2.82$ and 2.88 for $a$, $b$ and $c$, and $0.01,5.6$ and 10 for precision, chemical shift standard deviation and angle standard deviation, respectively.

We can obtain the dihedral angles for $D g \mathrm{FdII}_{\text {int }}$, by solving the Karplus equation with the values obtained for $a, b$ and $c$, for each pair of protons of the three cysteines Cys8, Cys14 and Cys50, using the chemical shifts obtained experimentally for each of them. These values are presented in Table 2, and are compared with the $\theta$ values obtained from the $D g$ FdII crystal structure [44].

Table 2 Comparison of the dihedral angle $(\theta) \mathrm{Fe}-\mathrm{S}-\mathrm{C} \alpha-\mathrm{C} \beta$ values for $D g \mathrm{FdII}_{\text {ox }}$ and $D g \mathrm{FdII}_{\text {int }}$. The data were obtained from the Xray structure for the oxidized state [31], and were extracted from the fitting presented in Fig. 4, for the intermediate state

\begin{tabular}{ccl}
\hline \multirow{2}{*}{ Cys } & \multicolumn{2}{c}{ Dihedral angle (degrees) } \\
\cline { 2 - 3 } & $D g \mathrm{FdII}_{\text {ox }}$ & $D g \mathrm{FdII}_{\text {int }}$ \\
\hline 8 & 68.3 & $261 \pm 8$ \\
14 & 259.5 & $265 \pm 20$ \\
50 & 87.7 & $268 \pm 15$ \\
\hline
\end{tabular}

deviation and angle standard deviation were 0.01, 5.6 and 10, respectively. The experimental NMR chemical shifts used were those available for $D g \mathrm{FdII}$, Thermococus litoralis $3 \mathrm{Fe} \mathrm{Fd}$ and Azotobacter vinelandii 7Fe Fd [54-56]. $\theta$ values were obtained from the X-ray structures of $D g$ and $A$. vinelandii Fds $[31,57,58]$

NOESY spectra, with 150-ms mixing times, were obtained for samples of $\mathrm{FdII}$ ox, $\mathrm{FdII}_{\text {int }}$ and fully reduced FdII, in order to study structural conformational changes in the protein, due to the opening of the disulfide bridge. Figure 5 shows the $\mathrm{H} \alpha / \mathrm{H} \beta$ correlation region between Cys18 and Cys42 of the NOESY spectra obtained for the different redox states of the protein. It can be seen that the NOE found for the $\mathrm{H} \alpha \mathrm{Cys} 18 / \mathrm{H} \beta$ Cys42 cross peak in FdII ox (Fig. 5, panel a) is less intense in the intermediate state (where an equilibrium between oxidized and intermediate states is present; Fig. 5, panel b) and disappears in the fully reduced sample (where all the protein molecules have an open disulfide bridge; Fig. 5, panel c).

\section{Discussion}

In order to understand the alterations detected in the hyperfine shifted signals of the ${ }^{1} \mathrm{H}$ NMR spectrum of $\mathrm{FdII}_{\text {int }}$ (Fig. 1), the sequence-specific assignments of the $\beta-\mathrm{CH}_{2}$ protons of Cys8, Cys 14 and Cys50 were first attempted. This was carried out using two-dimensional NOESY experiments with short mixing times (owing to the fast relaxation times of those protons affected by the cluster paramagnetism) and one-dimensional NOE experiments. The correlations obtained were described in the "Results" section, and are given in Table 1. It can be seen that the chemical shift of each $\beta-\mathrm{CH}_{2}$ pair of protons does not change drastically when compared with the corresponding shifts for $\mathrm{FdII}_{\mathrm{ox}}$, and that the chemical shifts of the assigned $\alpha-\mathrm{CH}$ protons (only detected for Cys8 and Cys14) are maintained. The sequence-specific assignment of Cys8 and Cys50 was carried out based on these observations. It is interesting 
Fig. 5 A region of the 600$\mathrm{MHz}{ }^{1} \mathrm{H}$ NOESY $(150-\mathrm{ms}$ mixing time) NMR spectra of $D g \mathrm{FdII}_{\text {ox }}$ (panel $a$ ), DgFdII ${ }_{\text {int }}$ (panel $b$ ) and $D g$ FdII red (panel c), at $300 \mathrm{~K}$. The arrow in (panel a) indicates the cross peak correlating the $\mathrm{H} \alpha$ proton of Cys 18 with the $\mathrm{H} \beta$ proton of Cys42. In panel $b$ this cross peak is less intense and disappears (panel c) when the protein is completely reduced

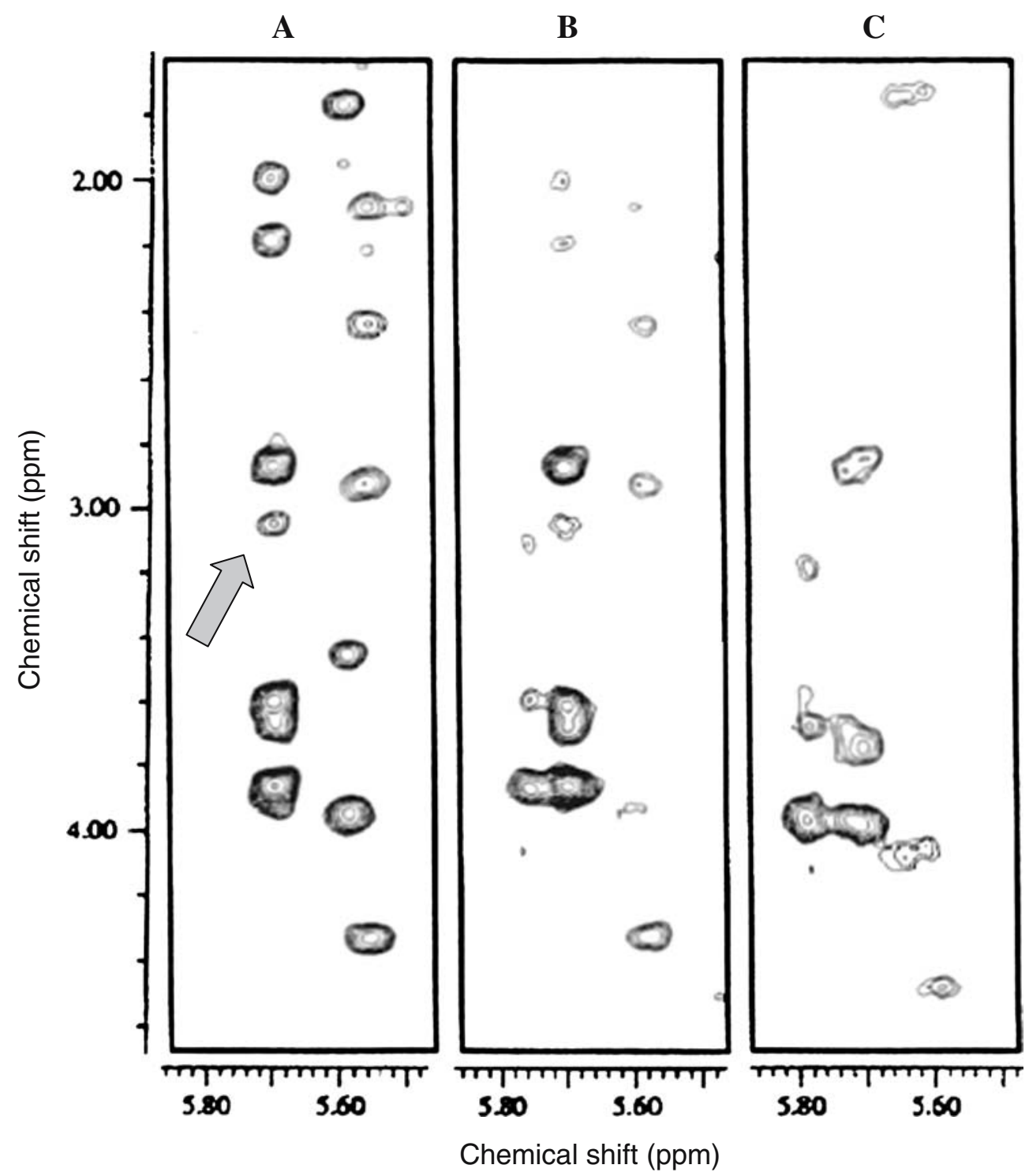

to note that the chemical shift spread of the $\beta-\mathrm{CH}_{2}$ proton resonances is less for $\mathrm{FdII}_{\text {int }}$ (they can be found between 8 and $24 \mathrm{ppm}$ ) compared with $\mathrm{FdII}_{\mathrm{ox}}$ (between 2 and $29 \mathrm{ppm}$ ). This suggests that rearrangements in the cluster environment, namely alterations in the dihedral angles $\mathrm{Fe}-\mathrm{S}-\mathrm{C} \beta-\mathrm{C} \alpha$ or changes in the iron spin coupling in the cluster, due to the opening of the $\mathrm{S}-\mathrm{S}$ bridge are taking place. It also suggests that the dihedral angles for the binding cysteines are becoming more equal on going from $\mathrm{FdII}_{\text {ox }}$ to $\mathrm{FdII}_{\text {int }}$ (if all the dihedral angles were the same all the $\beta-\mathrm{CH}_{2}$ chemical shifts would be equal). The notion that the iron atoms are more equivalent in the intermediate state has already been discussed using results obtained from Mössbauer spectroscopy [46].

The temperature dependence of the three pairs of $\beta-\mathrm{CH}_{2}$ resonances of the intermediate state (Fig. 3) displays typical behaviour that is found for all $[3 \mathrm{Fe}-$ $4 \mathrm{~S}^{+}$containing $\mathrm{Fds}$, including $D g \mathrm{FdII}_{\text {ox }}[62]$. The asymmetry found for the coupling between the three
$\mathrm{Fe}^{3+}(S=5 / 2)$ atoms is reflected in the NMR spectrum by the presence of Curie temperature dependence for one of the bound cysteines and anti-Curie dependence for the remaining two. The difference found for $\mathrm{FdII}_{\text {int }}$ is that it is no longer Cys50 that shows Curie behaviour [62]. Curie behaviour is now displayed by Cys14 and the parameters used in the spin-coupling model, already described for the oxidized form of $D g F$ dII [62], cannot explain the isotropic shift temperature dependencies of the three cysteinyl cluster ligands in $\mathrm{FdII}_{\text {int }}$, as the $3 \mathrm{Fe}$ cluster is in the same oxidation state. A value of $300 \mathrm{~cm}^{-1}$ was estimated for the magnetic exchange coupling constants between the iron spins in $\mathrm{FdII}_{\mathrm{ox}}$ [42] with $J_{12}=J_{13}=J, J_{23}=J+\Delta J$ and $\Delta J / J=0.02$, using $A$ values (coupling constant between the iron electronic spins and the $\beta-\mathrm{CH}_{2}$ nuclear spins) of $1 \mathrm{MHz}$, for the three irons sites, as estimated for a $[\mathrm{Fe}-\mathrm{S}]$ containing rubredoxin [80]. The set of $J$ values found for the [3Fe$4 \mathrm{~S}$ ] cluster of the $7 \mathrm{Fe}$ B. schlegelii [45] and R. palustris 
[66] Fds are also of the same order of magnitude as those found for $D g$. Using $A$ values of $1 \mathrm{MHz}$, Curie temperature dependence is always displayed (using different $J$ and $\Delta J$ values) by the cysteinyl $\beta-\mathrm{CH}_{2}$ protons that have the larger chemical shifts. For FdII ${ }_{\text {int }}$ the protons showing Curie dependence are those with the smaller chemical shifts (Cys14 using an average value for the $\beta$ $\mathrm{CH}_{2}$ pair). This behaviour is only possible if different $A$ values for each $\beta-\mathrm{CH}_{2}$ chemical shift pair are introduced. This is supported by the fact that the slopes of the curves are maintained, and the curves are displaced by a factor that could result from a change in the $A$ values. The Fe electron spin and ${ }^{1} \mathrm{H}$ nuclear spin coupling constant, $A$, is dependent on unpaired electron spin density at the ${ }^{1} \mathrm{H}$ nucleus and on the $\mathrm{Fe}-\mathrm{S} \gamma-\mathrm{C} \beta-\mathrm{C} \alpha$ dihedral angle. The observed change in temperature dependencies and chemical shifts could therefore result from either of these parameters. However, as the oxidation state of the $[3 \mathrm{Fe}-4 \mathrm{~S}]$ cluster is the same, +1 , for FdII $_{\text {ox }}$ and FdII $_{\text {int }}$ no extra spin density appears to be present at the cluster. The change in temperature dependence and chemical shift, on going from $\mathrm{FdII}_{\mathrm{ox}}$ to $\mathrm{FdII}$ int, must, then, result from a change in the dihedral angles at the cluster as a direct result of the loss of the S-S bridge between Cys 18 and Cys42. The different distribution of spin density over the cluster caused/allowed by the change in dihedral angles is detected as changes in the chemical shift and temperature dependencies for the $\beta-\mathrm{CH}_{2}$ protons (as the contact chemical shift is related to $A$ ).

With the data obtained when solving the Karplus equation, a positive value is found for parameter $a$ (see "Materials and methods" section), indicating that the $\pi$ mechanism of spin transfer is dominant, which is also the case for $[4 \mathrm{Fe}-4 \mathrm{~S}]$ systems. The curve in Fig. 4 was used to extract dihedral angle $\mathrm{Fe}-\mathrm{S} \gamma-\mathrm{C} \alpha-\mathrm{C} \beta$ information for $\mathrm{FdII}_{\mathrm{int}}$ as described in the "Results " section, and already applied to [4Fe-4S] containing Fds [76]. As can be seen in Table 2, the orientation of the $\beta-\mathrm{CH}_{2}$ protons with respect to the cluster iron atoms is more or less maintained in $\mathrm{FdII}_{\text {int }}$. However, as changes are seen in the chemical shifts, structural changes must be occurring at the cluster. It should be noted that small changes in the dihedral angles could cause large changes in the contact chemical shift. The actual difference seen for Cys 14 is $5.5 \pm 20^{\circ}$, while the differences for Cys 8 and Cys50 are more significant, being $192.7 \pm 8^{\circ}$ and $180.3 \pm 15^{\circ}$, respectively. One possible explanation is that the $\mathbf{S} \gamma$ atoms of Cys8 and Cys50 are both involved in $\mathrm{NH}-\mathrm{S} \mathrm{H}-$ bonds $(\mathrm{NH}-\mathrm{S}$ : Ala10-Cys8, Ala31-Cys8, Ala52-Cys50 and Ala54-Cys50) in the X-ray structure. The NHs of both Cys8 and Cys50 are also involved in $\mathrm{NH}-\mathrm{O} \mathrm{H}$-bonds, while the $\mathrm{NH}$ of Cys14 is not (it is $2.4 \AA$ from a S atom).

Direct evidence for the loss of the $\mathrm{S}-\mathrm{S}$ bridge between Cys 18 and Cys42 on going from $\mathrm{FdII}_{\mathrm{ox}}$ to $\mathrm{FdII}_{\text {int }}$ and finally to $\mathrm{FdII}_{\text {red }}$, was obtained by the loss of intensity of the cross peak that correlates $\mathrm{H} \alpha \mathrm{Cys} 18 / \mathrm{H} \beta$ Cys 42 found in a $150-\mathrm{ms}$ NOESY spectrum (previously assigned in FdII $\left._{\text {ox }}[45]\right)$.
The cleavage of this $\mathrm{S}-\mathrm{S}$ bridge is the catalyst that causes the structural changes that result in the modification of the cluster binding cysteine dihedral angles, which manifest themselves as changes in the chemical shifts and temperature dependencies of the $\beta-\mathrm{CH}_{2}$ protons. It has recently been shown from the superimposition of the aerobic and anaerobic three-dimensional structures of $D g$ FdII [53] that the disulfide bond (Cys18Cys42) in the aerobic structure has two conformations, which was also interpreted as an opening up of the covalent disulfide bond. Moreover, the $\mathrm{Fe}-\mathrm{S}$ cluster geometry in the anaerobic structure is different from that in the aerobic structure, with a maximum increase and decrease of 0.15 and $0.14 \AA$ for the $\mathrm{Fe}-\mathrm{S}$ bond length ranges, respectively. A similar difference in the $\mathrm{Fe}-\mathrm{S}$ cluster geometries was previously observed when recombinant $D g F$ dII was characterized spectroscopically [81]: differences in the paramagnetic envelope of the NMR spectra of both the recombinant and the native proteins already pointed to structural changes in the $[3 \mathrm{Fe}-4 \mathrm{~S}]$ cluster geometries.

\section{Concluding remarks}

NMR is a unique technique that can easily distinguish different redox states in $\mathrm{Fe}-\mathrm{S}$-containing proteins, giving information about the electronic structure of the cluster and detecting small alterations in the cluster environment as well as in the protein as a whole.

By using one-dimensional NOE experiments, twodimensional NOESY experiments with short mixing times and chemical shift temperature dependencies it was possible to sequence-specifically assign all the $\beta$ $\mathrm{CH}_{2}$ protons of the cysteines that bind the cluster and the $\alpha-\mathrm{CH}$ protons of Cys 8 and Cys14 in $\mathrm{FdII}_{\text {int. The }}$ sequence-specific assignment of the binding cysteines was also completed for $\mathrm{FdII}_{\mathrm{ox}}$ with the assignment of the $\alpha-\mathrm{CH}$ proton of Cys 50 .

The change in behaviour of the temperature dependencies for $\mathrm{FdII}_{\text {int }}$ compared with $\mathrm{FdII}_{\mathrm{ox}}$ indicated that the structure, specifically the $\mathrm{Fe}-\mathrm{S} \gamma-\mathrm{C} \beta-\mathrm{C} \alpha$ dihedral angles, near the $[3 \mathrm{Fe}-4 \mathrm{~S}]$ cluster changes. In order to model the temperature dependencies of the $\beta$ $\mathrm{CH}_{2}$ protons for $\mathrm{FdII}_{\text {int }}$ new $A$ values need to be introduced.

Experiments to calculate the $A$ values for both oxidized states need to be carried out (electron spin echo envelope modulation spectroscopy can be very useful in this matter, and will be pursued). The results obtained will allow a full understanding of the modifications in FdII $_{\text {int }}$ and calculation of the parameters that characterize the coupling between the irons in the cluster. A full structural characterization of the changes occurring in the $\mathrm{FdII}_{\text {int }}$ state is under way.

It can be concluded that the electronic properties of the $[3 \mathrm{Fe}-4 \mathrm{~S}]$ cluster are essentially modulated by the 'constraints' imposed by the polypeptide chain of the protein. 
It is remarkable that such a small protein, FdII, containing a $3 \mathrm{Fe}$ cluster and an internal disulfide bridge can be an electron sink $\left(3 e^{-}\right.$at the cluster and $2 e^{-}$at the $\mathrm{S}-\mathrm{S}$ bond). Such a multiple redox device can play unexpected roles in electron transfer and iron storage, considering also the easy cluster conversion processes $(3 \mathrm{Fe} \leftrightarrow 4 \mathrm{Fe})$ that may take place under physiological conditions [41].

Acknowledgements We would like to thank Ludwig Krippahl for his help with the computer software provided by him and used in this work. This work was supported by Fundação para a Ciência e Tecnologia and COST D2 1.

\section{References}

1. Holm RH (1992) Advances in inorganic chemistry, vol 38. Academic, San Diego

2. Johnson MK (1994) Encyclopedia of inorganic chemistry. In: King RB (ed) Wiley, Chichester, pp 1896-1915

3. Beinert H, Holm RH, Munck E (1997) Science 277:653-659

4. Beinert H (2000) J Biol Inorg Chem 5:2-15

5. Glaser T, Hedman B, Hodgson KO, Solomon EI (2000) Acc Chem Res 33:859-868

6. Noodleman L, Case DA (2000) Adv Inorg Chem 33:423-470

7. Calzolai L, Zhou Z-H, Adams MWW, LaMar GN (1996) J Am Chem Soc 118:2513-2514

8. Hunsicker-Wang LM, Heine A, Chen Y, Luna EP, Todaro T et al (2003) Biochemistry 42:7303-7317

9. Flint DH, Allen RM (1996) Chem Rev 96:2315-2334

10. Beinert H, Kennedy MC, Stout CD (1996) Chem Rev 96:23352373

11. Jarret JT (2003) Curr Opin Chem Biol 7:174-182

12. Cheek J, Broderick JB (2001) J Biol Inorg Chem 6:209-226

13. Dobbek H, Svetlitchnyi V, Gremer L, Huber R, Meyer O (2001) Science 293:1281-1285

14. Crane BR, Siegel LM, Getzoff ED (1995) Science 270:59-67

15. Doukov TI, Iverson TM, Seravalli J, Ragsdale SW, Drennan CL (2002) Science 298:567-572

16. Darnault C, Volbeda A, Kim EJ, Legrand P, Vernede X et al (2003) Nat Struct Biol 10:271-279

17. Svetlichnyi V, Dobbek H, Meyer-Klaucke W, Meins T, Thiele B et al (2004) Proc Natl Acad Sci USA 101:446-451

18. Nicolet Y, Cavazza C, Fontecilla-Camps JC (2002) J Inorg Biochem 91:1-8

19. Peters JW, Lanzilotta WN, Lemon BJ, Seefeldt LC (1998) Science 282:1853-1858

20. Thauer RK, Schönheit P (1982) Iron-sulfur proteins. In: Spiro TG (ed) Wiley-Interscience, New York, pp 329-341

21. Plank DW, Kennedy MC, Beinert H, Howard JB (1989) J Biol Chem 264:20385-20393

22. Golinelli MP, Chatelet C, Duin EC, Johnson MK, Meyer J (1998) Biochemistry 37:10429-10437

23. Mulholland SE, Gibney BR, Rabanal F, Dutton PL (1998) J Am Chem Soc 120:10296-10302

24. Cunningham RP, Asahara H, Bank JF, Scholes CP, Salerno JC et al (1989) Biochemistry 28:4450-4455

25. Kuo CF, McRee DE, Fisher CL, O'Handley SF, Cunningham RP, Tainer JA (1992) Science 258:434-440

26. Porello SL, Cannon MJ, David SS (1998) Biochemistry 37:6465-6475

27. Guan Y, Manuel RC, Arvai AS, Parikh SS, Mol CD et al (1998) Nat Struct Biol 5:1058-1064

28. Kiley PJ, Beinert H (2003) Curr Opin Microbiol 6:181-185

29. Demple B, Ding H, Jorgensen M (2002) Methods Enzymol 348:355-364

30. Alen C, Sonenshein AL (1999) Proc Natl Acad Sci USA 96:10412-10417
31. Tang Y, Guest JR (1999) Microbiology 145:3069-3079

32. Smith JL, Zaluzec EJ, Wery JP, Niu L, Switzer RL et al (1994) Science 264:1427-1433

33. Wu CK, Dailey HA, Rose JP, Burden A, Sellers VM, Wang BC (2001) Nat Struct Biol 8:156-160

34. Sellers VM, Johnson MK, Dailey HA (1996) Biochemistry 35:2699-2704

35. Dai S, Schwendtmayer C, Schurmann P, Ramaswamy S, Eklund H (2000) Science 287:655-658

36. Duin EC, Madadi-Kahkesh S, Hedderich R, Clay MD, Johnson MK (2002) FEBS Lett 512:263-268

37. Walters EM, Johnson MK (2004) Photosynth Res 79:249-264

38. Ugulave NB, Gibney BR, Jarret JT (2001) Biochemistry 40:8343-8351

39. Berkovitch F, Nicolet Y, Wan JT, Jarret JT, Drennan CL (2004) Science 303:76-79

40. Jameson GN, Cosper MM, Hernandez HL, Johnson MK, Huynh BH (2004) Biochemistry 43:2022-2031

41. Moura JJG, Macedo A, Palma PN (1994) Ferredoxins. Methods in enzymology. In: Peck HD Jr, LeGall J (eds) Inorganic microbial sulphur metabolism, vol 243. Academic, New York, chap 12

42. Bruschi M, Hatchikian C, LeGall J, Moura JJG, Xavier AV (1976) Biochem Biophys Acta 449:275-284

43. Bruschi M (1979) Biochim Biophys Res Commun 91:623

44. Kissinger CR, Sieker LC, Adman ET, Jensen JH (1991) J Mol Biol 219:693-715

45. Goodfellow BJ, Macedo AL, Rodrigues P, Wray V, Moura I, Moura JJG (1999) J Biol Inorg Chem 4:421-430

46. Macedo AL, Moura I, Surerus KK, Papaefthymiou V, Liu M, LeGall J, Münck E, Moura JJG (1994) J Biol Chem 269:80528058

47. Moura JJG, Moura I, Kent TA, Lipscomb JD, Huynh BH, LeGall J, Xavier AV, Münck E (1982) J Biol Chem 257:62596267

48. Moura I, Moura JJG, Münck E, Papaefthymiou V, LeGall J (1986) J Am Chem Soc 108:349-351

49. Butt JN, Sucheta A, Breton J, Thomson AJ, Hatchikian EC (1991) J Am Chem Soc 113:8948-8950

50. Conover RC, Park J-B, Adams MWW, Johnson MK (1990) J Am Chem Soc 112:4562-4564

51. Surerus KK, Münck E, Moura I, Moura JJG, LeGall J (1987) J Am Chem Soc 109:3805-3807

52. Moreno C, Macedo AL, Moura I, LeGall J, Moura JJG (1994) J Inorg Biochem 53:219-234

53. Hsieh YC, Liu MY, LeGall J, Chen CJ (2005) Acta Crystallogr D 61:780-783

54. Kent TA, Huynh BH, Münck E (1980) Proc Natl Acad Sci USA 77:6574

55. Emptage $\mathrm{MH}$, Kent TA, Huynh $\mathrm{BH}$, Rawlings J, OrmeJohnson WH, Münk E (1980) J Biol Chem 255:1793-1796

56. Xavier AV, Moura JJG, Moura I (1981) Struct Bonding 43:187-213

57. Armstrong FA, Butt JN, George SJ, Hatchikian EC, Thomson AJ (1989) FEBS Lett 259:15

58. Shen B, Martin LL, Butt JN, Armstrong FA, Stout CD, Jensen GM, Stephens PJ, LaMar GN, Gorst CM, Burgess BK (1993) J Biol Chem 268:25929-25939

59. Breton JL, Duff JL, Butt JN, Armstrong FA, Petillot Y, Forest E, Schafer G, Thomson AJ (1995) Eur J Biochem 233:937-946

60. Smith ET, Blamey JM, Zhou ZH, Adams MWW (1995) Biochemistry 53:219-234

61. Macedo AL, Palma N, Moura I, LeGall J, Wray V, Moura JJG (1993) Magn Res Chem 31:S59-S67

62. Macedo AL, Moura I, LeGall J, Huynh B, Moura JJG (1993) Inorg Chem 32:1101-1105

63. Bertini I, Ciurli S, Luchinat C (1995) Struct Bonding 83:1-53

64. Noodleman L (1988) Inorg Chem 27:3677-3679

65. Aono S, Bertini I, Cowan JA, Luchinat C, Rosato A, Viezolli MS (1996) J Biol Inorg Chem 1:523-528

66. Bertini I, Dikiy A, Luchinat C, Macinai R, Viezolli MS, Vincenzini M (1997) Biochemistry 36:3570-3579 
67. Gorst CM, Zhou ZH, Ma K, Teng Q, Howard JB, Adams MWW, LaMar GN (1995) Biochemistry 34:8788-8795

68. Vold RL, Waugh JS, Klein MP, Phelps DE (1968) J Chem Phys 48:3831

69. Inubushi T, Becker EDJ (1983) J Magn Res 51:128-133

70. Bertini I, Briganti F, Luchinat C, Scozzafava A, Sola M (1991) J Am Chem Soc 113:1237-1245

71. Macura SR, Ernst RR (1980) Mol Phys 40:95-117

72. Kumar A, Ernst RR, Wüthrich K (1980) Biochem Biophys Res Commun 95:1

73. Busse SC, LaMar GN, Yu LP, Howard JB, Smith ET, Zhou ZH, Adams MWW (1992) Biochemistry 31: 11952-11962

74. Donaire A, Gorst CM, Zhou ZH, Adams MWW, LaMar GN (1994) J Am Chem Soc 116:6841-6849
75. Cheng H, Grohmann K, Sweeney W (1992) J Biol Chem 267:8073-8080

76. Davy SL, Osborne MJ, Breton J, Moore GR, Thomson AJ, Bertini I, Luchinat C (1995) FEBS Lett 363:199-204

77. Imai T, Matsumoto T, Ohta S, Ohmori D, Suzuki K, Tanaka J, Tsukioka M, Tobari J (1983) Biochim Biophys Acta 743:91-97

78. Trower MK, Marshall JE, Doleman MS, Emptage MH, Sariaslani FS (1990) Biochim Biophys Acta 1037:290-296

79. Bertini I, Capozzi F, Luchinat C, Piccioli M, Vila AJ (1994) J Am Chem Soc 116:651-660

80. Werth MT, Kurtz Jr DM, Moura I, LeGall J (1987) J Am Chem Soc 109:273-275

81. Rodrigues P, Graça F, Macedo AL, Moura I, Moura JJG (2001) Biochem Biophys Res Commun 289:630-633 